\title{
ENSAIO SOBRE AS OBRAS CORPOS DE ANA NOROGRANDO NA QUEERMUSEU
}

Ana Norogrando ${ }^{1}$

A série Corpos teve sua origem numa visita a uma serralharia que produz e recupera queimadores de gás de lixo² do Aterro Sanitário de Minas do Leão (a $80 \mathrm{~km}$ de Porto Alegre - RS). ${ }^{3}$

Muitos queimadores estão destruídos e inutilizados. Eles são desprezados por não terem mais condições de recuperação para uso e apresentam todo tipo de falhas e imperfeições na sua estrutura e no seu visual. Nestas condições, seguem para o ferrovelho.

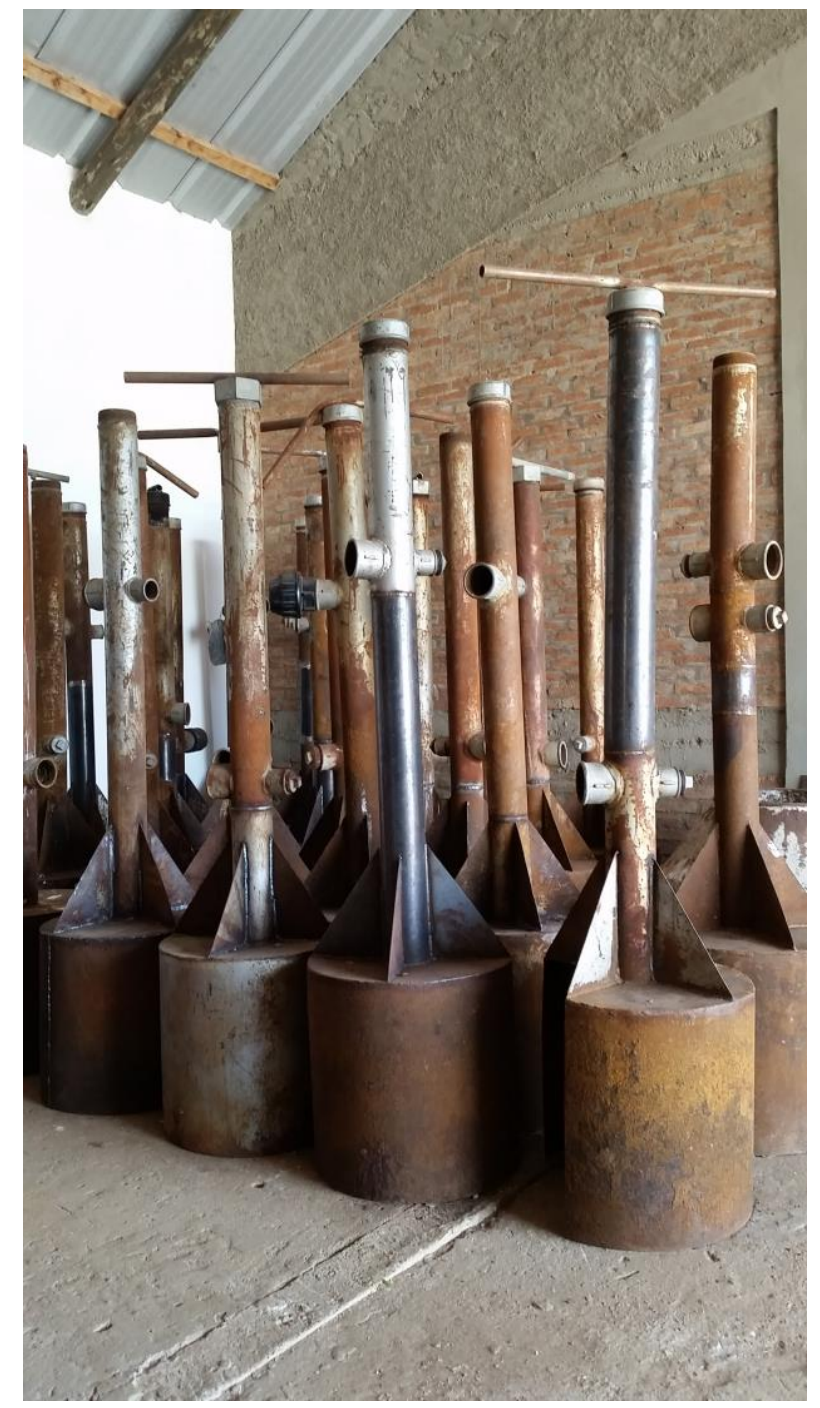

Figura 01-Queimdores de gás de lixo.

\footnotetext{
${ }^{1}$ Artista plástica, Rio Grande do Sul, Brasil.

${ }^{2} \mathrm{O}$ gás gerado pela decomposição do lixo, que tem metano altamente poluente, é queimado e vira gás carbônico, menos poluente à natureza.

${ }^{3}$ Nota da Organizadora: Texto original especialmente convidado para compor a Sessão de Ensaios Queermuseu: Cartografias da Diferença na Arte Brasileira.
} 
Algumas peças descartadas, com aproximadamente $2 \mathrm{~m}$ de altura e $50 \mathrm{~cm}$ de diâmetro, foram resgatadas. Uso esse termo, pois à primeira vista parecem figuras mutiladas - objetos estranhos e cheios de "defeitos". As rachaduras e fissuras, os rasgos e as perfurações, as imprecisões e ranhuras, todas as oxidações da superfície desses objetos foram instigadores e desencadearam este trabalho de reflexão artística.

Exatamente 29 peças rejeitadas foram elegidas para a realização da série Corpos. Os problemas e as pequenas diferenças estruturais presentes nas carcaças dos queimadores de gás contribuíram para estabelecer os conceitos que constituíram os Corpos que visualizei. Todos os aspectos marginais impregnados nesses objetos descartados: sua obsolescência, deficiência e a própria rejeição foram referências primordiais para a concepção das esculturas.

Cada escultura foi cuidadosamente elaborada observando a sua estrutura e todos os vestígios contidos em seu esqueleto de origem - os detalhes e incisões existentes, a textura e a cor do ferro oxidado foram preservados. O material obsoleto, defeituoso e rejeitado, interagiu com materiais contemporâneos. O ferro-velho incorporou e dialogou com artefatos industriais e naturais. A fusão deles com produtos do universo industrial foi feita com cautela para que pudessem dialogar com o conjunto e complementar a leitura e os conceitos referentes à cada escultura.

Cada Corpo é uma realidade em conexão intrínseca com sua origem e sua imagem transformada, assim, os fragmentos de manequins, a escolha da cor e os materiais industrializados foram variados e específicos para cada mensagem corporal construída, a complementar-se com a introdução de chapas metálicas, canos, tubos, conexões, mangueiras, parafusos, tecidos, cordas, tintas e outros elementos.

$\mathrm{Na}$ concepção de cada escultura a inserção de fragmentos de manequins foram fundamentais para integralizar o conceito e sua transformação visual e conceitual. Em geral, o emprego destas peças é muito comedido ou mínimo, em algumas esculturas, elas são subentendidas ou participam como pequenas insinuações do corpo humano.

A partir destas impressões - com ênfase no universo feminino, nas questões de gênero e socioculturais - cada obra pretende um significado ancorado numa visão empática, feminista e humana e pelo enquadramento do corpo em nossa sociedade. A sexualidade, a pluralidade, a diversidade, a liberdade, a opressão, a fragilidade, a rejeição, a dependência e o preconceito são fatores fortemente presentes na nossa cultura. Os Corpos tem a intenção de apontar muitas dessas fragilidades, impressões, transformações 
e agressões, de modo muito sutil e muito subjetivo, que também permitam interpretações de vivências e crenças pessoais.

A série apresenta corpos indefinidos, ambíguos que combinam tipos físicos femininos, masculinos e trans. Eles se interceptam e mostram variadas expressões a ultrapassar os conceitos estabelecidos por nossa cultura, libertando-os de qualquer preconceito e resignação. Nesse sentido, muitas foram as minhas motivações para a construção das esculturas da série Corpos.

Neste ensaio apresento algumas considerações pertinentes sobre cinco obras dessa série que foram selecionadas pelo curador Gaudêncio Fidelis para a exposição Queermuseu: Cartografias da diferença na Arte Brasileira - respectivamente: Corpo 1, Corpo 10, Corpo 16, Corpo 20 e Corpo 24.

O Corpo 1 trata da autodefesa constante que temos de ter, como individuo ímpar, em nossa sociedade. A figura apresenta um peitoral que sugere um escudo composto por duas partes: uma que sobressai - avança - e outra que se retrai - recua. Recorda-me uma guerreira que ora ataca, ora acovarda-se ou protege-se. Tudo num espaço limitado, contido por uma corda com suas pontas vermelhas, que atravessa um suporte metálico como a prenunciar um perigo inesperado. No anteparo que avança tem uma campânula metálica que sugere um seio e na metade que se recolhe temos a síntese obstruída deste símbolo feminino. O elemento estrutural que sugere o órgão genital está fechado nas duas extremidades com tampas vermelhas, como que protegido, lacrado e reprimido. 


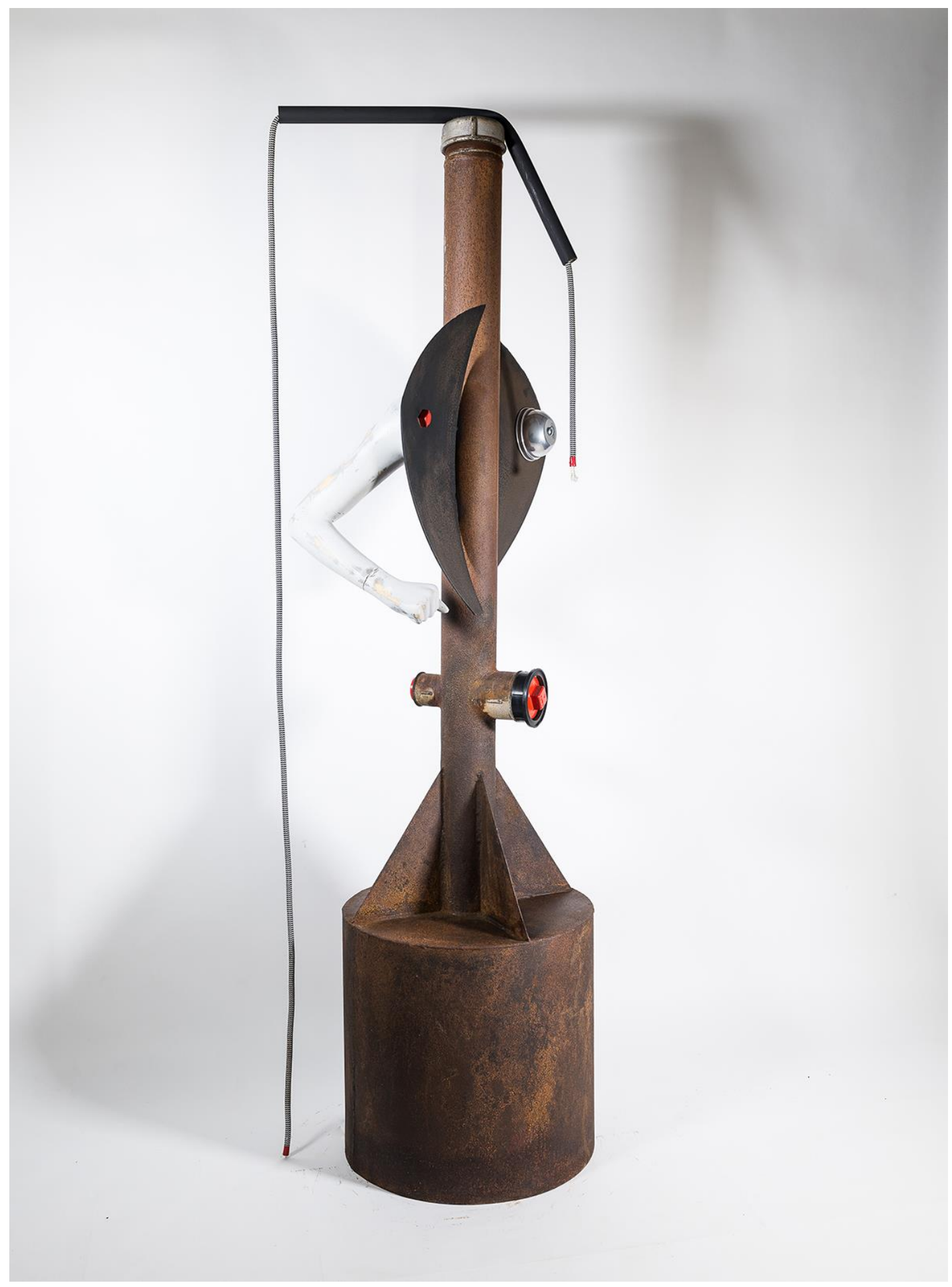

Figura 02 - Corpo 1

No Corpo 10 temos, pela posição dos braços e da mão, uma figura no compasso de uma dança - supostamente em par. Uma das extremidades dos sugeridos membros é interrompida por uma tampa vermelha que se contrapõe com o movimento curvo e delicado da mão do outro braço. Na parte superior, um arco como uma grinalda prende uma malha metálica oxidada - este elemento enfatiza o contraste entre a leveza do véu e 
seu real significado. Ao observamos a representação do órgão sexual feminino vemos que este é interceptado pelo órgão masculino que, como uma lâmina vermelha, pressupõe um coito nupcial de uma virgem ou um hibridismo sexual por uma "genitália transgênera" e assim ritma-se uma noiva, uma bailarina, uma corporificação ou encenação.

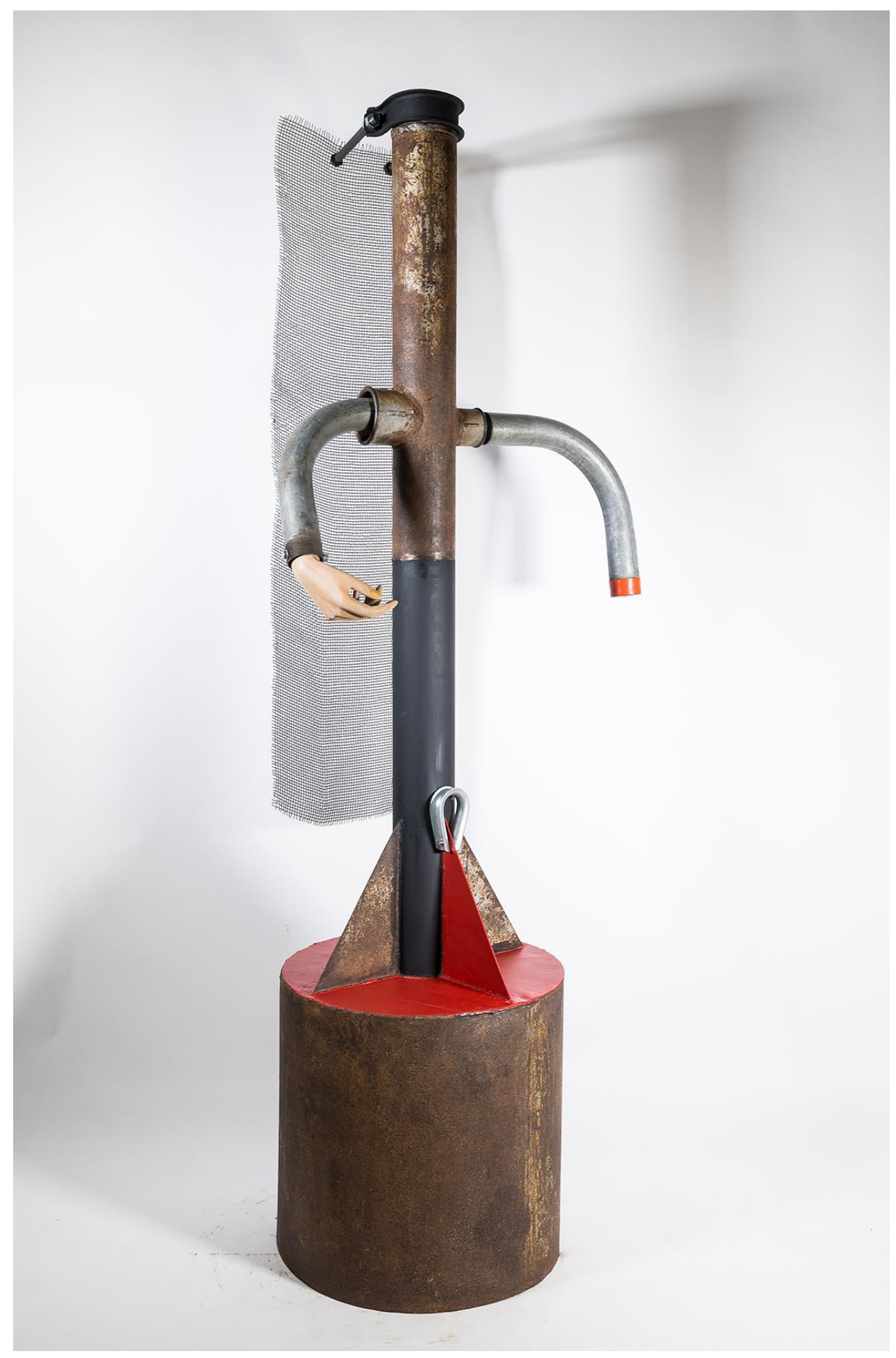

Figura 03 - Corpo 10 
No Corpo 16 três figuras são sugeridas pela composição dos braços: dois masculinos e musculosos e um feminino, branco e frágil. No primeiro momento, o entrelaçamento das peças sugere uma transa com três personagens, mas ao olhar com atenção podemos considerar um ataque sexual, um estupro coletivo - tão estatisticamente praticado. Este fato é enfatizado pelo órgão sexual masculino, ereto, vermelho com uma transparência vítrea e com a extremidade translúcida a sugerir a ejaculação.

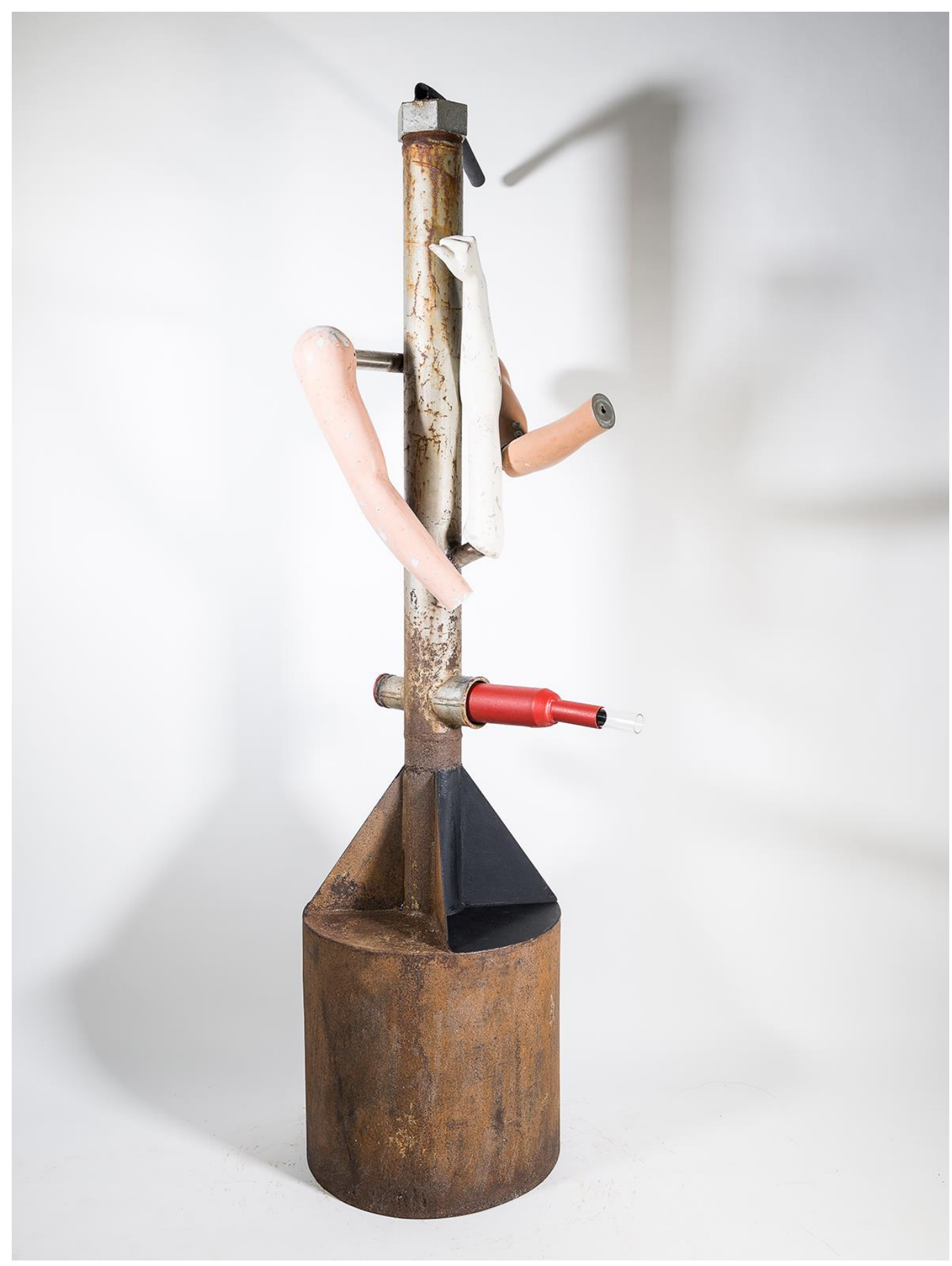

Figura 04- Corpo 16 
O Corpo 20 evidencia as interlocuções, contradições e/ou ambiguidades entre o feminino e o masculino. Um presumido braço em contrição é estendido por uma mão feminina longa e delicada que, ao mesmo tempo em que se expande em oração e em direção ao topo da figura, pede absolvição de seus pecados. Culpa, arrependimento ou agradecimento? Este conjunto contido na estrutura vertical da peça é complementado com um órgão fálico - um "pênis protuberante", que emerge de uma base azul que se conecta com os apêndices azul e metálico presos no vértice da figura como evocando aos céus a sua benção.

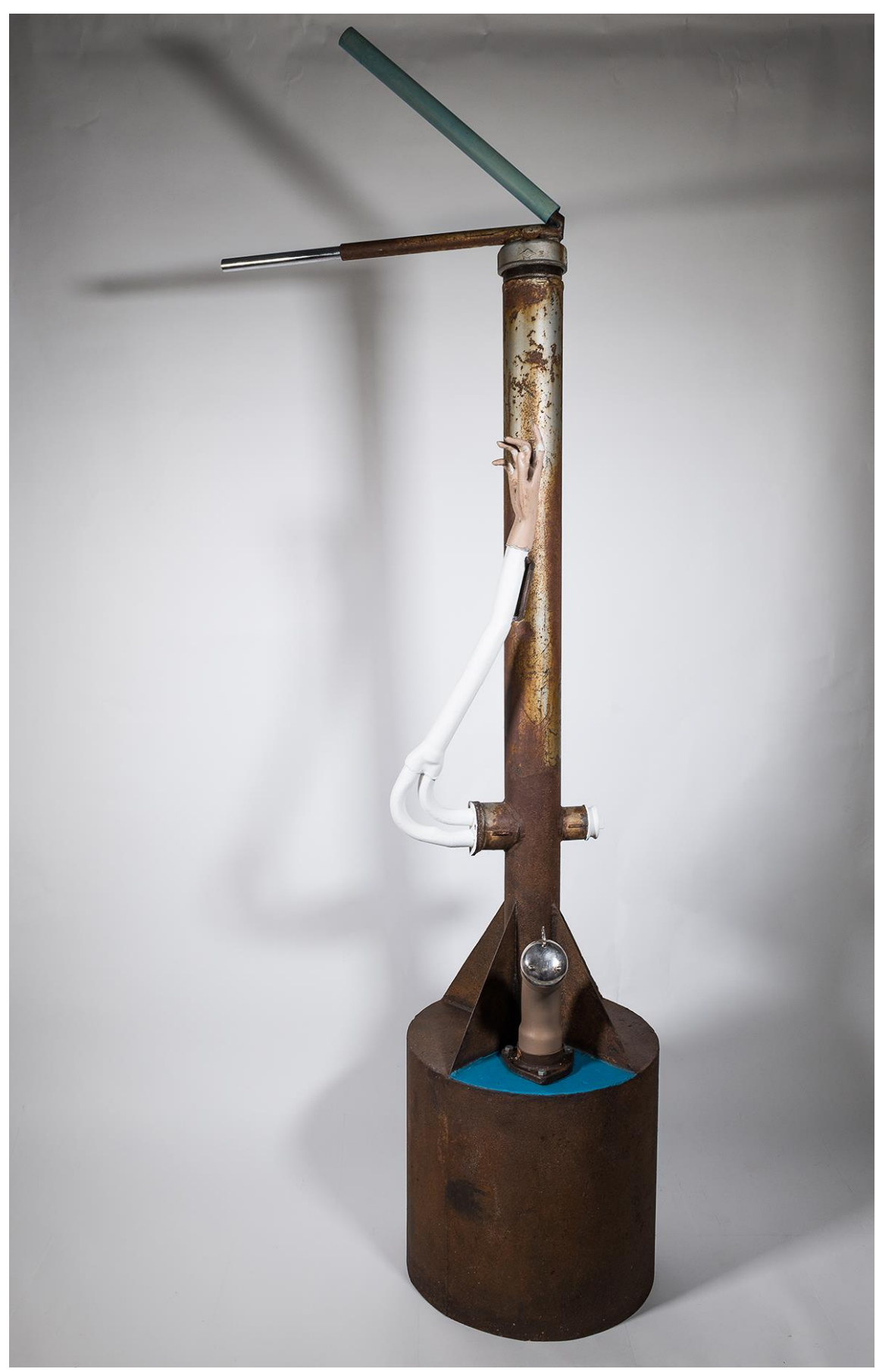

Figura 05- Corpo 20 
Corpo 24 revisa a homossexualidade e a sensualidade feminina. Duas pernas de manequim, ambas do lado direito são interligadas por uma mangueira flexível de aço permitindo variar suas posições: cruzá-las ou afastá-las em diferentes movimentos. Este conjunto transpassa por um cano de aço que finaliza do outro lado em um cano vermelho - única saída como se fosse uma fonte/vertente ou um esgoto/cloaca. Tudo é emoldurado por tecidos coloridos, leves e transparentes acentuando a sensualidade das pernas. Eles são suspensos numa barra de ferro fixa na tampa superior da escultura, na tentativa de dar estabilidade e harmonia à essa relação. Os tecidos de cores verde e azul de um lado dialogam com o tecido do outro lado que contem em sua estrutura essas duas cores. Essa composição cromática em superfície leve e fluída dá força ao equilíbrio e à dualidade das figuras.

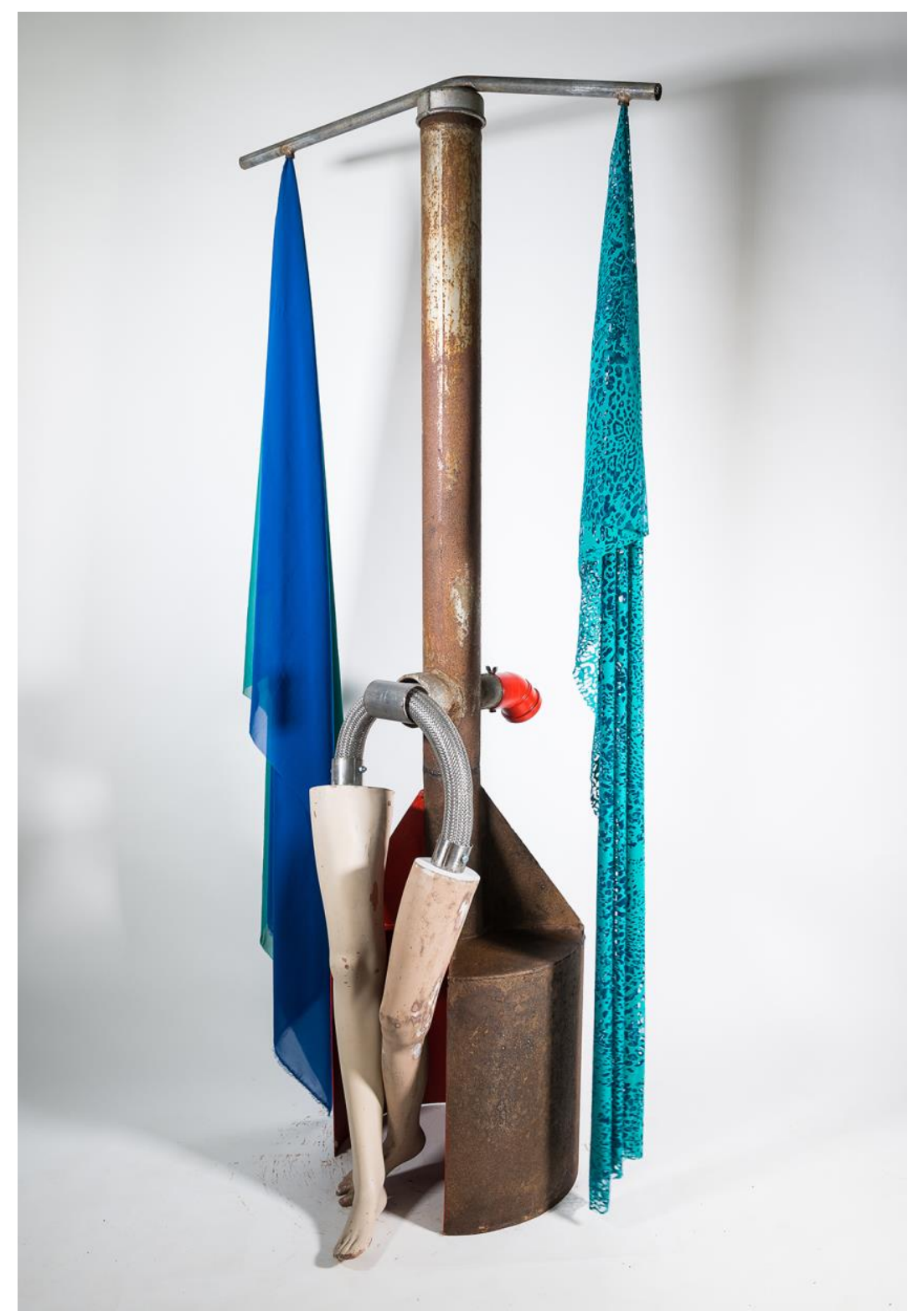

Figura 06 - Corpo 24 
A sexualidade, a pluralidade, a diversidade, a opressão, a fragilidade, a rejeição, a dependência, a falta de liberdade e o preconceito são fatores fortemente presentes na nossa cultura. Os Corpos têm a intenção de apontar muitas dessas fragilidades, impressões, transformações e agressões, de modo muito sutil e muito subjetivo, que também permitam interpretações de vivências e crenças pessoais. Cada Corpo traz uma verdade, uma realidade, uma humanidade ou um desespero - são por vezes, personificados ou sublimados. 